Artigo Original

\title{
O "match do século" e a "história esportiva" do xadrez - uma interpretação sociológica
}

\author{
Juliano de Souza \\ Wanderley Marchi Júnior \\ Centro de Pesquisa em Esporte, Lazer e Sociedade, Universidade Federal \\ do Paraná, Curitiba, PR, Brasil
}

\begin{abstract}
Resumo: O presente artigo configura uma síntese da dissertação de mestrado defendida por um dos autores com o título "O xadrez em xeque: uma análise sociológica da história esportiva da modalidade" (SOUZA, 2010). O problema de pesquisa que esteve em tela na dissertação consistiu na possibilidade de recuperar e compreender as transformações conjunturais e mercadológicas potencializadas no subcampo esportivo do xadrez, em nível de oferta e demanda da prática enxadrística, pela ocasião da final do campeonato mundial de 1972 e, em seguida, avaliar o que essas transformações representaram ou significaram no processo de construção da "história esportiva" da modalidade. Como hipótese de trabalho sustentou-se que durante o contexto histórico-social do chamado "match do século", a modalidade de xadrez conheceu a "fase de ouro" de sua "história esportiva", condição que, a partir da articulação empíricoteórica levada a efeito ao longo do estudo, se demonstrou comprovada.
\end{abstract}

Palavras-chave: Xadrez. Esporte. História.

\section{The "match of the century" and the "sports history" of chess - a sociological interpretation}

\begin{abstract}
This paper is a summary of the master's degree thesis defended by the author with the title "Chess in check: a sociological analysis of its sporting history" (SOUZA, 2010). The research problem that the thesis has had on screen was the ability to recover and understand the conjunctural and market potentiated changes in chess sport's subfield at the level of supply and demand of the practice on the occasion of the end of the world championship 1972. And then evaluate what these changes meant or represented in the construction of "sports history" of chess. As a working hypothesis it was argued that during the historical and social context of the "match of the century", chess has known the "golden phase" of its "sports history", a condition that, from the joint empirical-theoretical carried out during the study, was proven.
\end{abstract}

Keywords: Chess. Sports. History.

\section{Introdução}

O presente artigo configura uma síntese da dissertação de mestrado defendida por um dos autores com o título "O xadrez em xeque: uma análise sociológica da história esportiva da modalidade" (SOUZA, 2010). O problema de pesquisa que deu origem a essa investigação resulta do descontentamento desperto acerca da forma com que a história do xadrez foi e tem sido escrita e difundida entre os estudiosos dessa prática, ou seja, a partir de um modelo de periodização definido em função de transformações macroestruturais balizadas a partir de grandes saltos temporais, conformando, sobretudo, uma abordagem que prioriza quase que exclusivamente o desvelar de nomes e datas.

Some-se a tal prognóstico, o fato dessas mudanças a nível macro não constituírem o ponto de partida mais interessante para substanciar uma análise sociológica da "história esportiva" da referida modalidade, até mesmo por conta de tal proposta de periodização conduzir a uma descrição e análise puramente institucionalista quando senão a uma abordagem incapaz de perceber e, além disso, apreender os deslocamentos estabelecidos em sua devida complexidade na relação entre a oferta e a demanda social dessa prática esportiva.

O que se pode admitir, nesse particular, é que esses macroperíodos estão carregados de suas próprias rupturas, as quais quando trazidas à tona ajudam na tarefa de reconstituir alguns capítulos da "história esportiva" do xadrez ou, melhor dizendo, a recuperar alguns elementos pertinentes ao processo de esportivização dessa prática e, mais que isso, a compreender algumas das contingências inerentes à constituição e consolidação do xadrez como subcampo concorrente no interior do campo esportivo. 
A par dessa última premissa, assumida, inclusive, como norte do estudo, argumenta-se então que a "história esportiva" do xadrez vem a ser mais bem decodificada e transparecida ao se observar, por exemplo, que em cada um dos ciclos de campeonatos mundiais dessa prática - 0 que representa um recorte temporal relativamente pequeno (em média três anos) - uma série de deslocamentos e ressignificações foram negociadas pelos agentes no interior do microcosmo social que a própria modalidade constituía, reorientando assim a dinâmica da oferta e da demanda, da prática e do consumo enxadrístico.

Durante o processo de estruturação do que aqui está sendo chamado de "história esportiva" relativamente autônoma do xadrez foram disputados 47 campeonatos mundiais oficializados num período compreendido entre 1886 a 2012. Dessa forma, ao levar-se em conta que cada um desses micro-ciclos foi marcado e constituído por seus próprios avanços e recuos, demonstrou-se impossível e inviável percorrer-se pelas linhas histórico-sociológicas de todos os campeonatos mundiais de xadrez. Daí a decisão e, ao mesmo tempo, justificativa em definir como ponto de partida de compreensão dessa trama que constitui a "história esportiva" do xadrez, as transformações potencializadas na modalidade no ciclo de um único campeonato mundial.

Deste modo, e para via da análise sociológica aqui proposta, optou-se em recortar o campeonato mundial de xadrez de 1972 como universo intelígivel onde se assenta a presente discussão. Mais especificamente, a problemática de pesquisa que esteve em tela na dissertação consistiu na possibilidade de recuperar e compreender as transformações conjunturais e mercadológicas potencializadas no subcampo esportivo do xadrez, em nível de oferta e demanda da prática enxadrística, pela ocasião da final do campeonato mundial de 1972 e, em seguida, avaliar o que essas transformações representaram no processo de construção da "história esportiva" da modalidade.

Vale notar que o referido confronto foi realizado em Reykjavik na Islândia entre os dias onze de julho a primeiro de setembro de 1972. Nessa ocasião, disputaram o título o enxadrista soviético Boris Spassky e o enxadrista norteamericano Robert James Fischer. O confronto terminou com a vitória do norte-americano por
12,5 a 8,5 colocando fim a uma hegemonia soviética de 24 anos no subcampo do xadrez. A série de 21 partidas realizadas entre os dois jogadores em 1972 foi divulgada e ficou conhecida como o "match do século".

Paralelamente ao problema investigativo situado, assumiu-se a hipótese de trabalho que, durante o período do "match do século", a modalidade de xadrez conheceu a "fase de ouro" de sua "história esportiva", demarcando então um momento de singularidade histórico-estrutural denominada de cristalização deste subcampo no interior do campo esportivo, justamente por evidenciar um período em que o entrelaçamento entre os contornos espetaculares, simbólicos e miméticos conferidos à oferta da prática enxadrística representou a consolidação da modalidade frente à lógica de distribuição e consumo das demais práticas esportivas no contexto histórico-social em questão.

Nas páginas que seguem procura-se, portanto, apresentar alguns dos elementos analíticos que vieram a consubstanciar a hipótese de partida que subsidiou o referido estudo. Antes, no entanto, de explorar tais elementos é necessário situar aqueles procedimentos teórico-metodológicos que foram adotados na pesquisa, até porque tanto a seleção e dimensionamento dos materiais empíricos quanto a posterior interpretação dos mesmos e articulação segundo um quadro teórico coerente se deu através de tais procedimentos.

\section{Encaminhamentos teórico- metodológicos}

"Toda sociologia digna do nome é "sociologia histórica" (MILLS, 1975, p. 159). Eis uma das teses sustentadas pelo sociólogo norte-americano Charles Wright Mills em seu clássico texto "A imaginação sociológica" de 1959. Para este autor, as ciências sociais são disciplinas fundamentalmente históricas. Daí sua insistência em que os cientistas sociais recorram aos materiais históricos e ao método comparativo em suas análises, de modo que possam elaborar as perguntas sociológicas mais adequadas, bem como respondê-las.

Ao reivindicar uma proposta de historicidade para o desenvolvimento dos estudos sociológicos, Mills rejeita o rótulo atribuído à sociologia como ciência social do presente. Nessa linha de raciocínio, o autor se junta a outros sociólogos de vanguarda como, por exemplo, Norbert Elias e 
Pierre Bourdieu. A propósito, Elias (1980) recomenda a formação de cientistas sociais atentos às dimensões de longo prazo, ao passo que Bourdieu (1990a, p. 57-58), insiste que a sociologia é de ponta a ponta histórica, muito embora pondere que a história necessária para exercer seu ofício dificilmente pode ser encontrada

Como maneira de pensar o mundo social, à sociologia cabe então a tarefa de recombinar presente e passado, micro e macro-história, local e global, referências de curto prazo e de longo prazo, sociedades próximas e distantes no tempo e espaço. Por sua vez, a escrita da história para não ficar fadada, a fornecer apenas uma visão ideológica de quem a escreve, quando senão uma opinião sobre a autenticidade das fontes, deveria se substanciar em modelos teóricos gerativos sistematizados no âmbito das ciências sociais (ELIAS, 2001).

Inclusive, pensando nesse dilema é que Mills adverte que, "[...] se os historiadores não têm "teoria", podem proporcionar material para escrever-se a história, mas não podem êles mesmos, escrevê-la" (MILLS, 1975, p. 158). Com base nessa leitura ainda é que Bourdieu defende que "[...] la separación entre la sociología e la historia es una división desastrosa, y que esta totalmente desprovista de justificación epistemológica: toda sociología debería ser histórica y toda historia sociológica" (BOURDIEU; WAQCUANT, 2008, p. 126).

Pautados nesse estatuto transdisciplinar reivindicado por tais autores, é que se decidiu, portanto, transitar pelas chamadas linhas histórico-sociológicas que definiram a constituição do subcampo esportivo do xadrez em sua lógica de concorrência frente ao universo das práticas esportivas. Nesse sentido, é possível dizer que o presente estudo constituiu-se (1) em uma investigação histórico-sociológica amparada no método comparativo e (2) em uma pesquisa empírica guiada por teoria ou, melhor dizendo, em uma abordagem na qual se procurou tratar os materiais históricos sob o crivo dos modelos teóricos de Elias e Bourdieu, ambos retomados em um sentido complementar no estudo.

Prosseguindo na exposição dessa lógica argumentativa, convém reiterar que para Mills toda pesquisa sociológica que se apeteça sólida e consistente deveria empregar materiais históricos e comparados. $E$ isso essencialmente porque os estudos sociológicos não históricos, isto é, que desconsideram o papel da historicidade na construção da realidade social, tendem a serem estáticos e curtos ou então limitados a ambientes (MILLS, 1975, p. 162). Por sua vez, o método comparado, tal como trabalhado na abordagem sociológica de Mills, diz respeito a comparações entre diferentes sociedades, diferentes épocas, enfim, entre diferentes estruturas sociais.

Em síntese, o estudo comparado das estruturas sociais ou o mínimo de conhecimento histórico sobre as descontinuidades estruturais constituintes do mundo social é fator de suma importância para uma análise sociológica que se ambicione reflexiva. Além disso, essa postura metodológica demonstra extrema vantagem científica com relação a estudos que se concentram sobre uma suposta unidade nacional recortada no tempo e espaço, trans-histórica e sem conexões com a estrutura de outras sociedades e outras épocas.

$\mathrm{Na}$ construção da problemática de pesquisa aqui em tela, procurou-se então conservar uma devida sensibilidade comparativa para perceber o quão limitado seria reportar-se à final do campeonato mundial de xadrez de 1972, tomando por referência cronológica unicamente aquele momento histórico ou então referenciando espacialmente e circunscrevendo a análise apenas no cenário geográfico em que se protagonizou o referido confronto, quando senão ponderando os efeitos dessa conjuntura no interior de uma sociedade isolada sem restabelecer as devidas conexões com outros domínios de tempo-espaço.

Nesse particular, antes de se avançar às chamadas análises situadas que prescrevem uma leitura estrutural das relações e disputas simbólicas no interior dos campos e subcampos em voga bem como nas aproximações que engendram, decidiu-se recorrer e explorar preliminarmente as tendências de desenvolvimento estrutural em longo prazo, tanto no que se refere à "história esportiva" relativamente autônoma do xadrez quanto à história social da Guerra Fria. A respeito desses ajustes Mills novamente corrobora:

Se quisermos compreender as transformações dinâmicas de uma estrutura social contemporânea, teremos de distinguir sua evolução a longo prazo, e em têrmos desta indagar: qual a mecânica da ocorrência dessas tendências, que transformam a estrutura da sociedade? É com essas indagações que nossa 
preocupação chega ao auge, relacionando-se êste com a transição de uma época para outra, e com o que podemos chamar de estrutura de uma época. [...] Cada época quando devidamente definida, é um "campo de estudo inteligível", que revela a mecânica do processo histórico a ela peculiar (MILLS, 1975, p. 165).

Segundo Mills (1975) para se realizar um estudo histórico-sociológico, primeiramente é preciso distinguir e situar 0 processo de desenvolvimento de determinada sociedade, prática ou objeto em termos de longo prazo, para em seguida então contrapor, ou melhor, comparar essa estrutura espacial-temporal relativamente ampla com a estrutura de um momento específico, compondo-se e fundamentando-se assim, um quadro de análise que permita estruturar e situar o objeto de estudo na condição de um "campo de estudo inteligível".

Nesse ponto Mills se aproxima muito de Norbert Elias, para quem o quadro de mudanças sociais estruturalmente definidas na perspectiva de longo prazo fornece apontamentos para uma compreensão dos processos de curto prazo (ELIAS, 2006, p. 231). Importa notar que na estruturação de seu modelo configuracional, Elias não desconsidera as tendências de curto prazo, mas procura localizá-las no interior dos processos sociais de longo termo.

Não obstante esse dimensionamento, é preciso admitir que Elias quase não se ateve ao estudo das estruturas sociais contextualizadas num intervalo de tempo-espaço relativamente curto, o que, Ihe predispõe como um sociólogo mais atento à continuidade histórica e, por vezes, um pouco menos sensível as descontinuidades e rupturas que só são identificadas e transparecidas na realidade social mediante o estudo minucioso, circunscrito e situado.

A propósito, esse tratamento sociológico mais circunscrito a determinado recorte de espaçotempo parece ter sido contemplada mais detidamente na obra de Pierre Bourdieu. $\mathrm{Na}$ elaboração de seu modelo de análise sociológica dos campos, Bourdieu se propôs, em primeira instância, a tornar inteligíveis os mecanismos que asseguram e prescrevem o funcionamento desses universos num determinado momento histórico, para em seguida então, trazer à luz os fundamentos ocultos de dominação que aí se perpetuam.

No entanto, é importante reiterar que essa ordem de prioridades não impediu que Bourdieu reservasse, ainda que de forma periférica, um espaço para análise estrutural dos antecedentes históricos dos campos, e sem a qual, tornar-se-ia praticamente impossível entender como se estruturam tais espaços de lutas, coerções, trocas, e, além disso, como se constituem e se definem os objetos em disputa (BOURDIEU, 1990b, p. 210).

Dadas essas considerações de valor heurístico, resolveu-se, portanto, estruturar esse objeto de estudo como "campo de estudo inteligível", já que o mesmo abrangeu a articulação entre as estruturas de curto prazo (estrutura do momento) e as estruturas de longo prazo (história) numa dinâmica que procura superar, dentro de certos limites, a tricotomia "presente-passado-futuro" e, além disso, garantir que o sociólogo não seja meramente "jornalístico" em sua profissão e nem muito menos "profético" (MILLS, 1975, p. 167).

Logo, ao ser revisitado o subcampo do xadrez em 1972, foi preciso se reportar ao cenário político, econômico e cultural de um mundo bipolar que se desenhou mais concretamente após o final da Segunda Guerra Mundial em 1945 e se estendeu até aproximadamente os primeiros anos da década de 1990. Também houve a necessidade de tomar por referência a longa história do xadrez, sobretudo, a partir do momento em que a referida prática começou a demonstrar alguns contornos mais esportivizados na Inglaterra vitoriana.

Quanto ao uso dos materiais históricos solicitados ao longo da pesquisa, percebeu-se a importância de realizar um levantamento dos antecedentes acadêmico-científicos e culturais inerentes ao raio de ação dos agentes no interior dos campos de produção material e simbólica pertinentes à discussão suscitada, quais sejam, o subcampo esportivo do xadrez, o campo jornalístico e o campo de produção sociológica e historiográfica.

Nesse propósito, cabe ressaltar que a variedade de materiais históricos resgatados nessa imersão empírica se constituiu como o fio condutor que levou a recompor, para além de um exercício historiográfico, o espaço das relações, dos eventos, das lutas, das regularidades, dos fatos, das datas, enfim, dos agentes que fizeram história, ou melhor, que fizeram a "história esportiva" relativamente autônoma da modalidade de xadrez. 
Por sua vez, o uso dos materiais históricos se deu em conformidade com 0 modelo metodológico esboçado por Bourdieu no capítulo do livro "Razões práticas" que tem como título "Por uma ciência das obras" (BOURDIEU, 2007). Em tal ocasião, o sociólogo francês apresenta um modelo de análise dos bens históricos e culturais que tem por objeto a correspondência (ou dialética) entre duas estruturas homólogas, isto é, entre a estrutura interna de uma obra - forma e conteúdo - e a estrutura externa de sua produção.

Essa perspectiva de leitura lança luz ao embate historiográfico em torno de velhas e conhecidas polarizações como "verdade versus mentira", "fontes primárias versus fontes secundárias", já que a imposição legítima das realidades históricas, segundo Bourdieu (2007), resulta primeiramente de lutas pelo monopólio de trazer à existência as coisas propriamente nomeadas pelos produtores culturais no interior dos mais distintos campos sociais. Nesse caso, o que interessa a Bourdieu e também para a realização dessa pesquisa, é problematizar as condições sociais de produção e recepção dos materiais históricos, bem como os usos sociais a que os mesmos se prestam.

Sobre a distribuição desses materiais históricos como requisitos e ao mesmo tempo ferramentas de compreensão das respectivas estruturas sociais de curto prazo e longo prazo delimitadas, foi realizada a seguinte divisão:

(1) Para avaliar e objetivar a estrutura de longo prazo que a "história esportiva" relativamente autônoma da modalidade de xadrez constitui, tomou-se como ponto de partida as considerações desenvolvidas nas chamadas literaturas enxadrísticas, com ênfase àquelas obras de caráter histórico que circularam no interior do subcampo esportivo em questão.

(2) Com relação ao entendimento do embate entre o bloco capitalista e socialista durante 0 contexto social da Guerra Fria, buscou-se sustentação nos referenciais historiográficos produzidos sobre a temática.

(3) Para leitura de curto prazo, mais precisamente, do delineamento e direcionamento da oferta e demanda da modalidade de xadrez durante o "match do século" em 1972, também foi conferido centralidade às literaturas enxadrísticas, reservando um maior espaço para análise de reportagens e imagens veiculadas na mídia impressa e nos próprios livros de xadrez durante aquele período e agora mais recentemente em 2008, quando o match de 1972 novamente foi trazido à tona por conta do falecimento de Bobby Fischer.

Feitas essas ressalvas de ordem teóricometodológica que, por sua vez, sinalizam para a possibilidade de tratamento da "história esportiva" do xadrez a partir da inter-relação e confrontação de tendências históricas de longo prazo e curto prazo, convém então apresentar nas páginas que seguem alguns dos principais argumentos analíticos que reiteram a validade da hipótese de partida do estudo diante do problema de pesquisa formulado.

\section{Resultados e Discussões}

No decorrer dessa pesquisa, foi demonstrada a constituição histórico-estrutural do subcampo esportivo do xadrez tomando por referência de análise alguns dos principais eventos campeonatos mundiais e torneios - disputados entre a metade final do século XIX e os últimos anos da década de 1970. Nesse percurso, foram recuperadas algumas rupturas inerentes à constituição deste subespaço, rupturas essas condicionadas às exigências do mercado e que, portanto, remetiam a tomadas de posição dos especialistas e produtores culturais em conformidade com as sanções impostas pela nova lógica mercantil que passou a vigorar no contexto pós-Revolução Industrial inglesa.

Um primeiro indício dessa conjuntura pode ser elencado ao se retomar as publicações do enxadrista inglês Howard Staunton nos anos de 1847 e 1860 bem como a confecção de um padrão standart para as peças de xadrez em sua homenagem no ano de 1849 (LOUREIRO, 2006, p. 1012). Ambas as inserções ao mesmo tempo em que reforçavam ou conferiam um senso de distinção ao jogador inglês também conformavam um sentido de oferta das práticas esportivas condizente com as demandas mercadológicas que se faziam presentes e atuantes no interior dos mais distintos locus e universos sociais.

Outro exemplo esclarecedor, dentre vários outros destacados ao longo do estudo, se deu em 1873 quando o enxadrista Wilhelm Steinitz, já residindo na Inglaterra, obteve uma coluna no Jornal The Field e Fígaro, que destinavam um espaço editorial para divulgar as práticas esportivas em potencial destaque na sociedade inglesa daquela época, quais sejam, rúgbi, futebol, atletismo, golfe, remo e o recém inventado tênis (GARCIA, 2006, p. 10-11). 
Nesse contexto de constituição de um campo relativamente autônomo das práticas esportivas na sociedade inglesa do final do século XIX, O xadrez se alocava em uma posição privilegiada em relação às demais modalidades esportivas emergentes, até porque a prática enxadrística, na condição de jogo ou passatempo preferido das elites européias, já havia se cristalizado há mais de um século nas teias de interdependências, o que, em última análise, predispunha seus representantes como detentores de um capital simbólico historicamente legitimado e, por isso, decisivo nas disputas entre agentes e instituições esportivas no contexto do amadorismo (SOUZA, 2010).

É importante frisar, inclusive, que a experiência de esportivização da prática enxadrística só veio a se materializar quando o jogo foi contrastado a uma série de mudanças estruturais que tiveram lugar e destaque na sociedade inglesa do século XIX (SOUZA; STAREPRAVO; MARCHI JÚNIOR, 2011). Dito de modo mais preciso, a transição do xadrez de jogo ou lazer intelectual para uma prática com contornos altamente esportivizados só se deu quando essa prática foi combinada a essa nova instituição inglesa alicerçada então sob as bases do associativismo e burocratização parlamentar, qual seja, o clube.

Dessa forma, enquanto na França a cena enxadrística se edificava principalmente nos Cafés sob o signo do acúmulo de capital cultural e na Alemanha a prática regular do xadrez figurava como elemento fortemente educacional e formador de caráter, na Inglaterra o enxadrismo se revestia de um significado novo que priorizava os componentes racionais e burocráticos em detrimento da informalidade e prescritivismo com que se conduzia a prática do xadrez nos círculos sociais europeus nos séculos XVII e XVIII (LASKER, 1999; SAIDY, 1972; KASPAROV, 2004).

Se com base nessa análise é correto dizer que a Inglaterra se constituiu, portanto, como locus que favoreceu a esportivização do jogo do xadrez, por outro lado, é necessário lembrar que foi nos Estados Unidos que se objetivou pioneiramente e de forma mais sistemática o processo de mercantilização e profissionalização da prática enxadrística. O exemplo mais incisivo do que está sendo dito, talvez seja a realização do primeiro campeonato mundial de xadrez realizado oficialmente nos Estados Unidos em 1886.

Um dos protagonistas sociais decisivos nesse período foi justamente o enxadrista Wilhelm Steinitz, a essas alturas já residindo nos Estados Unidos. Steinitz se esforçou para elevar o status da prática enxadrística a um esporte e, ao mesmo tempo, profissão. Nesse contexto, o xadrez passou por um rápido crescimento na sociedade norte-americana tanto em termos de popularidade como de inovações técnicas no jogo. Houve também uma proliferação de torneios que corriam semanas e contavam com altas premiações em dinheiro. A imprensa escrita, por sua vez, impulsionou a oferta da modalidade de modo a contribuir com a formação de um contingente de praticantes de xadrez para além da esfera do rendimento e da alta performance esportiva (STEINITZ, 1891; FINE, 1983; LANDSBERG, 1993; KASPAROV, 2004; GARCIA, 2006)

De modo adjacente, essa nova lógica começou a se consolidar também pela Europa permitindo assim aos principais enxadristas mundiais disputarem torneios tanto no velho continente quanto nos Estados Unidos. No entanto, essa proliferação de torneios de xadrez com dimensões espetaculares teve uma decaída durante o contexto da Primeira Guerra Mundial, retornando após esse período sem, todavia, manter as mesmas proporções iniciais com que esse fenômeno foi dimensionado no mundo préPrimeira Guerra, ainda que a conservar um mesmo sentido mercadológico recobrado nas condições sociais anteriores (FINE, 1983; KASPAROV, 2004; GARCIA, 2006)

Esse conjunto de relações sociais estruturantes no subcampo do xadrez corresponde a uma primeira ruptura incisiva demarcada no sentido de oferta da prática enxadrística. Uma segunda ruptura contundente, por conseguinte, seria aquela que se daria nos países do Leste Europeu, especialmente, na antiga União Soviética (URSS). Nesse sentido, se por um lado, pode-se dizer que as experiências mais incisivas de esportivização e mercantilização do xadrez tiveram sua gênese no interior da sociedade inglesa e norte-americana, por outro, pode-se afirmar que as experiências mais expressivas de massificação do xadrez foram estabelecidas na URSS das primeiras décadas do século $X X$. 
Dessa forma, é permissível sustentar o argumento de que nos países de orientação capitalista uma das maiores especificidades do subcampo esportivo do xadrez a partir dos anos 1880 dizia respeito ao fato de que as relações entre os agentes e estruturas envolvidas nessa prática esportiva eram reguladas e mediadas muito particularmente pelo mercado de bens materiais e simbólicos ao passo que nas sociedades de orientação exclusivamente socialista as relações estabelecidas no subcampo esportivo do xadrez, sobretudo a partir dos anos 1920 , eram reguladas pela burocracia estatal e pelas tomadas de posição governamentais (FINE, 1983; LASKER, 1999; KASPAROV, 2006).

É claro que essas variações se retroalimentam de modo que a economia do mercado não estava ausente no subcampo do xadrez na União Soviética e nem muito menos a alta racionalização ideológica do Estado no que tange ao gerenciamento das modalidades esportivas expresso, por vezes, no acúmulo de capital político - se fazia remota no subcampo do xadrez consolidado na sociedade consumista norteamericana. O que se pode admitir, portanto, é que no interior de uma sociedade de orientação socialista as relações entre esporte e Estado no contexto histórico-social em tela se sobrepunham, por assim dizer, às relações entre esporte e mercado, ao passo que em uma sociedade de orientação capitalista essa ordem tendia a se inverter.

Com rigor, essa dinâmica de funcionamento do subcampo esportivo do xadrez é fundamental para entendermos 0 processo de concorrência histórica que essa modalidade estabeleceu frente aos demais esportes em sua "história esportiva" relativamente autônoma. Na União Soviética, o xadrez - prática esportiva associada consensualmente à ideologia comunista - era tratado como uma causa de Estado. Na condição de modalidade diferenciada por acumular um alto volume de capital intelectual e simbólico em sua forma e sentido de oferta, o xadrez soviético possibilitava aos seus mestres e grandes mestres, isto é, os enxadristas de ponta, salários diferenciados em relação aos cidadãos comuns e aos atletas de outras modalidades esportivas (LASKER, 1999; KASPAROV, 2005; LOUREIRO, 2006; EDMONDS; EIDINOW, 2007).

Além disso, os jogadores profissionais de xadrez da URSS assim como os atletas das demais modalidades eram considerados como funcionários do Estado e no interior dessa hierarquia de distribuição das práticas culturais, o enxadrismo, por sua vez, ocupava posição dominante ainda que, por mais contraditório que se pareça, das duzentas escolas de especialização esportiva que a União Soviética mantinha regularmente na transição dos anos 1960 para 1970 apenas sete delas ofertavam xadrez. Em contrapartida, tal prática se constituía como um componente curricular obrigatório nas escolas primárias e secundárias soviéticas se concretizando dessa maneira como a principal via de formação de um habitus enxadrístico no interior dos países de orientação político-social comunista (SAIDY, 1972; LASKER, 1999; JOHNSON, 2007).

Já nos países de economia capitalista, a lógica de formação dos habitus esportivos se mantinha prioritariamente condicionada aos ideais e valores do mercado. No caso do xadrez, esse processo de formação dos habitus tinha seu equivalente na difusão de produtos associados diretamente ao enxadrismo para além da zona de consumo formada por aqueles grupos sociais com experiências consolidadas nessa prática ao longo de suas histórias.

Com o surgimento dos meios de comunicação de massa no mundo pós-Segunda Guerra, a difusão da prática enxadrística passou a ser condicionada de modo radicalmente novo pelas sanções do mercado e pelo subsequente desenvolvimento de uma sociedade de consumo, ultrapassando, inclusive, as tendências de formação do gosto a partir da herança cultural familiar e das ações centralizadas nas políticas estatais de esporte e lazer (SOUZA, 2010).

Por conseguinte, a concorrência da modalidade de xadrez frentes aos demais esportes no campo esportivo tendia, no contexto de desenvolvimento dos meios de comunicação de massa, a ser minimizada ou até mesmo anulada. Isso, por sua vez, não quer dizer que o subcampo do xadrez tenha se mantido resistente as demandas midiáticas. Como se tem argumentado até aqui, ao longo de sua "história esportiva" relativamente autônoma, a atribuição de contornos mercantis e espetaculares à prática enxadrística foi um dos fundamentos cruciais para a esportivização do jogo e para sua consolidação como um dos primeiros subcampos esportivos modernos (SOUZA, 2010). 
Nesse sentido, a dificuldade da modalidade de xadrez em se firmar no pólo dominante do campo esportivo no contexto da sociedade de consumo não se devia a uma recusa de seus representantes e estruturas a entrar no "jogo mercadológico", mas, dentre outros fatores, se explica em função da hierarquia moral de distribuição do capital intelectual e corporal no campo esportivo e na sociedade mais ampla como um todo. Vale notar que em termos de circulação dos artefatos e bens culturais, não resta dúvidas, de que aquelas práticas esportivas que priorizam o corpo, a continuidade do movimento e o descontrole controlado das pulsões tendem a se constituir como esfera dominante no setor de vendas e comercialização dos bens esportivos.

Em contrapartida, as práticas esportivas que supostamente enfatizam mais os aspectos cognitivos e mentais em relação ao corporal tendem a ser encerradas em segundo plano no campo esportivo atraindo a atenção $e$ despertando 0 interesse particularmente de públicos restritos e que possuem um relativo grau de capital cultural, muito embora sempre existam as devidas exceções a serem situadas. Nem mesmo a posição dominante consolidada pela URSS no subcampo do xadrez após a Segunda Guerra foi suficiente para alocar o enxadrismo em um patamar de oferta e consumo semelhante ao futebol e as modalidades integrantes do programa olímpico.

Com base, portanto, nesses apontamentos introduzidos, é possível dizer que ao longo da "história esportiva" do xadrez, foi, sobretudo, suas primeiras décadas na condição de prática concorrente no campo esportivo que então representou uma maior visibilidade social para seus adeptos e aficionados, visibilidade essa, expressa na internacionalização dos torneios, na inserção da imprensa escrita e de investidores no subcampo esportivo do xadrez. Como se terá a possibilidade de acompanhar, essa condição só viria a ser superada na década de 1970 e por conta da realização do chamado "match do século".

No período que sucedeu a Primeira Guerra, o xadrez começou a perder sua representatividade no universo dos esportes, até porque a criação da Copa do Mundo de Futebol em 1930 e a realização dos Jogos Olímpicos de Los Angeles em 1932 viriam a demarcar o início de um período em que os grandes eventos esportivos e os grupos aristocráticos a eles ligados passariam a deter o monopólio das ações no campo esportivo de modo que as práticas esportivas não inclusas no rol olímpico e que não mobilizassem mundialmente as massas a exemplo do futebol estariam condenadas, sob o peso das devidas demandas sociais e simbólicas em jogo, a cair no ostracismo e se encerrar cada vez mais dentro de seus próprios universos e círculos de interesse (SOUZA, 2010).

No caso do xadrez ainda existe o imperativo da modalidade desde 1927 sediar uma espécie de Olimpíada própria denominada de "Torneio das Nações", a qual foi criada oportunamente após o fracasso da inclusão desse esporte nos Jogos Olímpicos de Paris em 1924 quando então foi realizado um torneio individual que contou com a participação de apenas dezoito países, fato esse que, em última análise, acabou levando o Comitê Olímpico Internacional (COI) a não reconhecer o xadrez como modalidade integrante do programa olímpico (FINE, 1983; SAIDY; LESSING, 1974; LASKER, 1999).

Após um quarto de século de indisposições entre o $\mathrm{COI}$ e a FIDE (Fédération Internationale des Échecs), finalmente o "Torneio das Nações" passou a se chamar Olimpíadas de Xadrez, ainda que seus adeptos e representantes, mesmo sem essa oficialização, insistissem em atribuir o jargão de olímpico a sua modalidade o que, mais uma vez, reforça a categoria da distinção social como um dos fundamentos centrais e decisivos na construção e consolidação da "história esportiva" do xadrez. Por sua vez, essa concessão do termo olímpico pelo COI foi conferida desde que a FIDE não se valesse dos atributos e símbolos olímpicos (anéis, bandeiras, hino), uso esse que, por sinal, só séria permitido apenas a partir de 2001 quando o xadrez foi reconhecido oficialmente como esporte olímpico pela instituição (LOUREIRO, 2006).

Durante o período que se inicia em 1948 e vai até o início da década de 1970, a concorrência da modalidade de xadrez no campo esportivo, igualmente ao que já vinha se estabelecendo no período entreguerras, também se constituiu sob as bases da informalidade midiática e da oferta social da prática enxadrística especialmente para círculos sociais restritos. E isso, dentre outros fatores, porque a ortodoxia instaurada no subcampo do xadrez por conta da hegemonia 
soviética expressa no monopólio dos títulos em disputa nos Campeonatos Mundiais e nas Olimpíadas de Xadrez, não propiciara um clímax esportivo apto a mobilizar um contingente de consumidores, o que, de certa forma, tendia a inviabilizar a incursão da mídia dominante e dos potenciais investidores e patrocinadores no subcampo esportivo em questão.

A propósito, é sempre importante lembrar que uma das mais evidentes características psicossociais inerente à prática enxadrística se refere ao fato da mesma possibilitar, em função de seus atributos esportivos e lúdicos, um contexto de fruição muito específico e diferente da maior parte dos esportes; um contexto de fruição onde se predomina uma espécie de emoção "refreada" e um controle severo das pulsões tanto por parte dos atletas quanto dos torcedores. Esse sentimento específico, por sua vez, só é desperto naqueles agentes que possuem os códigos da modalidade e o sentido de jogo impresso em sua forma de ver e apreciar a referida prática. Nessa circunstância inferida, aqueles que não possuem os pressupostos psicossociais e técnicos para a leitura do jogo são reduzidos a categoria de leigos e, além disso, tendem a não reconhecer a emoção específica que a prática do enxadrismo desperta.

Se não bastasse essa economia emocional vigente no subcampo do xadrez que pouco favorecia uma tomada de posição mais expressiva dessa modalidade no campo esportivo, ainda tinha-se o elemento da ortodoxia no subcampo que tornava a prática de xadrez potencialmente inapta a cativar um público mais heterogêneo e jovem. Talvez seja, inclusive, por conta desse entendimento que muitos dos organismos e instituições sociais posicionadas dominantemente no campo esportivo se manifestam resistentes ao monopólio das conquistas esportivas na figura de uma nação, estado, cidade, clube, visto que as estratégias de conservação da estrutura de distribuição dos títulos e das consagrações esportivas, a partir de um determinado tempo, estão fadadas a levar a monotonia e ao tédio, condicionando alguns esportes a uma possível perda de visibilidade pelo afastamento gradual e circunstancial da mídia e, o que é mais grave, pelo desinteresse dos consumidores.

Em que pese, no entanto, essa leitura sobre a posição historicamente subordinada do enxadrismo em relação à distribuição e circulação das práticas esportivas no espaço concorrencial que elas próprias vieram historicamente a estruturar, no contexto do "match do século" em 1972 o xadrez alcançou uma posição de relativo prestígio e visibilidade no campo esportivo mundial, a qual foi traduzida na ressignificação de seu patamar de oferta e consumo, ainda que por um período relativamente curto conforme aludem alguns dos materiais empíricos consultados durante a pesquisa (MORAN, 1972; GONZÁLEZ, 1972; SEGAL, 1972; CORDOVIL, 1972; MECKING, 1973; BJELICA, 1992). Observe-se o dimensionamento desse quadro nos seguintes trechos:

Nunca antes un acontecimiento ajedrecístico había repercutido a los ojos del público como esta "cumbre de Reykjavik". Los motivos han sido muchos y de diversa índole: un sugestivo choque de ideologías, estilos y personalidades, que ha dado como resultado el match más emocionante y accidentado de la historia del juego-ciencia. Por vez primera en los últimos 20 años la disputa del título mundial se alejava del Kremlin para alojarse en la remota Islandia, cuyas bajas temperaturas convivieron por espacio de 53 días con el "ardiente pugilato de los 64 escaques". Los protagonistas "llegan", y hasta el más modesto aficionado cruza apuestas especulando con el consabido interrogante ¿quién ganará? Las emociones de Reykjavik son transmitidas por prensa, radio y televisión a toda la afición ávida de reproducir ante el tablero las alternativas del match. Los teletipos teclean si cesas jugada tras jugad... algebráico, descriptivo, jeroglíficos... da lo mismo; el ajedrez se está internacionalizando. La literatura ajedrecística comienza a agotarse en varias capitales europeas y americanas; aficionados o no, todos se sienten identificados con las alternativas que se van sucediendo dentro y fuera de un tablero situado a miles de kilómetros de la mayor parte del mundo (GONZÁLEZ, 1972, p. 287).

Quer possua poderes fantásticos ou não, sozinho Fischer já fez pelo xadrez mais do que qualquer outro grande mestre moderno. Quase da noite para o dia, ele transformou o antigo e hermético território dos grandes mestres num fascinante e turbulento mundo de intrigas e movimentos espetaculares. Nos Estados Unidos, agora, os clubes de xadrez andam tão movimentados quanto os supermercados, e os livros sobre xadrez saíram de prateleiras nos fundos das livrarias para as vitrinas. Mesmo no Brasil, termos misteriosos, como defesa siciliana, gambito do rei ou fianqueto, já são usados com descuidada intimidade por muitos principiantes. Na Guanabara, uma barraca montada na areia de Copacabana pelo Centro de Educação de Xadrez, com doze tabuleiros tem recebido mais adeptos do que em qualquer outra época. E em Curitiba, nos tabuleiros do Passeio Público, as tradicionais tampinhas de cerveja usadas em partidas de damas foram 
substituídas por peças de xadrez (REVISTA VEJA, 9-8-1972, p. 62-63).

"Bobby" Fischer ha hecho por el ajedrez más que todos los campeones del mundo juntos, pues ha logrado que el juego se popularice de forma jamás soñada. Durante el "match" con Spassky acaparó la atención de la prensa mundial y del gran público. Se puso de moda en todas partes y en los Estados Unidos una fábrica de piezas de ajedrez tuvo que trabajar las 24 horas, ya que se veía imposibilitada para atender los pedidos; una canción "La balada de "Bobby" Fischer", la emitían cientos de emisoras [...] En todo el mundo se vendieron más libros de ajedrez en un mes que en otras ocasiones durante un año, y en la mayor parte de las ciudades, se agotaran. Gentes que jamás habían hablar del ajedrez aprendieran a mover las piezas; el resultado de las partidas, así como los movimientos, se esperaban con ansiedad, y en todos los círculos, en todos los cafés, se veía a gentes reproduciendo y discutiendo con calor las partidas. En Paris, el ajedrez se puso de moda hasta en las "boites" donde los jóvenes alternaron los bailes con el mundo mágico de las sesenta y cuatro casillas. En Bogotá grandes tableros murales instalados en plazas públicas, permitían a los aficionados seguir las incidencias del juego, mientras se cruzaban importantes y singulares apuestas; y nada digamos de los países, como Rusia, donde ya el ajedrez era un espectáculo de masas. La semilla está sembrada en todos los países de la tierra, y con Fischer un nuevo capítulo se abre en el mundo del ajedrez, y con su victoria se beneficiaran todos los ajedrecistas que, ignorados hasta a hora, comenzarán a tener cierta popularidad (MORAN, 1972, p. 81).

Como se nota nos excertos supracitados, no contexto dos anos 1970 por conta do "match do século", a modalidade de xadrez, de fato, conheceu a "fase de ouro" de sua "história esportiva". Essas fontes avaliativas, dentre inúmeras outras solicitadas ao longo da pesquisa, indicam de modo insofismável uma recondução do movimento oferta-demanda da referida prática esportiva em função da final do campeonato mundial de xadrez de 1972. Entretanto, compete advertir que tal corpus empírico mobilizado ao longo do estudo não apenas retrata as relações de oferta espetacular da modalidade e de consumo enxadrístico em 1972 e pelos anos que seguiram, mas, antes de tudo, se constituem em indicativos do próprio processo sugerido.

Em outras palavras, tanto as literaturas enxadrísticas reveladoras de um habitus enxadrístico e da percepção que os especialistas em xadrez tiveram desse contexto histórico-social específico quanto as próprias reportagens e imagens veiculadas na mídia impressa internacional com o maior propósito de "noticiar" as dimensões de oferta da modalidade, se tratam de materiais que não apenas indicaram os rumos que o xadrez tomou no campo esportivo mundial no contexto do "match do século", mas de forma bastante nítida de materiais que também promoveram esse processo de ruptura (SOUZA, 2010).

Tendo isso sido admitido, algumas questões e interpretações de ordem sociológica merecem ser pontuadas com base nesses três fragmentos trazidos à guisa de ilustração e síntese da investigação empírica desenvolvida na pesquisa de mestrado posta em apreciação neste artigo. Em primeiro lugar, é importante atentar para o fato de que tanto a produção literária quanto a produção jornalística referentes à final do campeonato mundial de xadrez de 1972 atribuíram um papel central à figura de Fischer para explicar as relações de oferta e demanda da modalidade de xadrez nesse período históricosocial.

Até certa medida é compreensível essa articulação e ênfase discursiva estabelecida no subcampo do xadrez e no campo midiático em torno da imagem de Fischer. Como se sabe, o mercado dos bens culturais, dentre os quais se inclui o esporte, produz continuamente ídolos e heróis que tendem a ser apresentados ao público consumidor como verdadeiros elementos-síntese de determinados processos protagonizados no campo esportivo. No entanto, essa ênfase por razões de ordem mercadológica em protagonistas isolados, não explica do ponto de vista científico o porquê dos arrancos ou recuos de determinadas práticas esportivas serem evidenciados de tempo em tempo no contexto de cada sociedade específica ou da sociedade global.

Assim sendo, a principal função da pesquisa sociológica tal como a que deu origem a este artigo, consiste em problematizar, para além das primeiras impressões dos agentes, quais os fatores sociais que concorrem muitas vezes de forma oculta e sem planejamento para que determinados processos que fazem o mundo de uma maneira qualquer e não de outra sejam possíveis. No caso do xadrez, portanto, pode-se afirmar que não foram atos isolados e desarticulados resultantes da ação de agentes solitários e com interesses unívocos que alavancaram o processo de cristalização do xadrez no campo esportivo de 1972 a 1975 . Em contrapartida, não foi também uma arquitetura 
racionalmente planejada para um fim específico que animou essa elevação momentânea do xadrez a um patamar de visibilidade e prestígio no campo esportivo mundial.

Como se viu até aqui a "história esportiva" do xadrez se trata de um processo que vem sendo construído a partir de continuidades e rupturas que se evidenciaram mais explicitamente a partir do momento em que essa prática se fez circular no interior da Inglaterra vitoriana e dos Estados Unidos do final do século XIX. Viu-se também que a partir dos anos 1920 se iniciou um processo de massificação enxadrística na União Soviética, até hoje sem precedentes. Ambas as experiências foram conduzidas sob os efeitos de expansão de um mercado enxadrístico a partir dos campeonatos mundiais e demais torneios importantes, muito embora na URSS essa prática tenha sido atrelada aos ideais do Estado e servido, portanto, de apoio à doutrina comunista.

De 1948 até 1972 a URSS manteve a hegemonia de títulos mundiais no subcampo esportivo do xadrez. Essa estrutura ortodoxa, por sua vez, não coligia com os interesses do mercado esportivo em expansão pelo mundo, uma vez que o monopólio de um país, clube ou qualquer outra instituição esportiva por muito tempo a frente de uma modalidade tende a reduzir o componente catártico contido no consumo dessa mesma prática, já que é possível antecipar os resultados e prever o curso dos acontecimentos. No caso do xadrez, isso ajuda a explicar a redução de sua potencialidade mercadológica e, portanto, a sua restrição a um público bastante seleto ao longo de mais de duas décadas.

Desde o início dos anos 1960, no entanto, a estrutura ortodoxa arranjada no subcampo esportivo do xadrez com a União Soviética no pólo dominante começou a demonstrar alguns sinais de estar seriamente ameaçada. Isso, dentre outras coisas, se articulou especialmente em função da emergência dos Estados Unidos como um potencial concorrente da URSS não só no âmbito do xadrez, mas de todos os esportes e domínios sociais possíveis, uma vez que ambos os países rivalizavam socialmente pela chamada Guerra Fria.

Em 1972, Bobby Fischer, melhor preparado técnica e psicologicamente que seu oponente Spassky, construiu ao longo de um mês o primeiro - e até hoje o único - título de campeonato mundial de xadrez dos Estados Unidos. Esse evento foi divulgado e transmitido no mundo inteiro sob a rubrica de "match do século". O xadrez nunca foi tão consumido e assistido no mundo. Aumentou-se significativamente a demanda de livros e tabuleiros de xadrez, para além dos círculos já socializados com essa prática esportiva (SOUZA, 2010).

Isso, no entanto, não foi fruto de uma estratégia racionalizadora do mercado, mas teve como principal mola propulsora o fato de aquela final em 1972 ter materializado mimeticamente o embate político da Guerra Fria travado na configuração social mais ampla. Essa conjuntura, por conseguinte, ao vir ser apropriada pelo campo midiático e conduzida pelo mercado de bens simbólicos acabou transformando o xadrez num produto mais comercializável, se bem que menos pelo que essa prática trazia de atrativo em si e mais pelos componentes miméticos acionados. A esse processo por conta de sua singularidade histórica e estrutural deu-se o nome de cristalização do xadrez no campo esportivo.

\section{Considerações Finais}

A combinação entre a abordagem sincrônica e diacrônica nesse estudo foi fundamental para se avançar no entendimento rigoroso e nãofantasioso de alguns dos rumos que a modalidade de xadrez (na figura de seus agentes e estruturas) trilhou no contexto do campeonato mundial de xadrez de $1972 \mathrm{e}$, de uma forma mais ampla, ao longo da "história esportiva" da modalidade. Se, como foi demonstrado ao longo do artigo, é evidente que houve uma reorientação da dialética oferta-demanda da modalidade de xadrez por conta do "match do século", menos autoevidente seria afirmar que este momento representou a "fase de ouro" dessa modalidade no espaço de concorrência esportiva.

No entanto, o exame da estrutura de longo prazo que compreende então a denominada "história esportiva" do xadrez e, mais que isso, a confrontação dessas tendências de longo alcance com a estrutura situada de uma época específica, a saber, com o contexto social que abrangeu a final do campeonato mundial de xadrez de 1972 (1970-1975), permitiu, por sua vez, confirmar a hipótese de partida sustentada no estudo, tendo em vista que tanto o período que precedeu esse recorte temporal definido quando o que veio a suceder, não superaram, em termos de oferta 
espetacularizada, divulgação midiática e de consumo dos eventos, produtos e bens enxadrísticos de modo articuladamente global, este momento estrutural da "história esportiva" da modalidade que teve como aparato simbólico as lógicas que permearam o "match do século".

A principal conclusão desse estudo, nesse sentido, é que a elevação do xadrez ao status de uma prática esportiva de visibilidade mundial entre os anos de 1970 a 1975 - num período que teve como ponto alto a decisão do título mundial de xadrez de 1972 protagonizada entre o norteamericano Robert James Fischer e o soviético Boris Spassky em pleno contexto dramático da Guerra Fria - se constituiu de forma proporcionalmente eficaz ao grau de desconhecimento das causas e efeitos dos comportamentos consumistas instituídos na realidade social mediante um movimento muito mais amplo de consolidação do mercado esportivo global.

Como uma última observação a ser tecida, chama-se a atenção para a importância de ser cada vez mais cultivado esse tipo de investigação no campo da Sociologia e História do Esporte no Brasil. A combinação e confrontação de tendências de curto prazo e longo prazo para a interpretação de um fenômeno polissêmico e cada vez mais globalizado como o esporte demonstra-se de extrema valia para 0 entendimento de alguns processos e contraprocessos sociais que vieram a culminar com a conformação de um mercado esportivo que orienta decisivamente, a partir de estratégias fundadas no desconhecimento do social e em apelos altamente emocionais, o comportamento dos agentes nas mais distintas manifestações do esporte na sociedade. O desvelamento dessa lógica, sem dúvida alguma, é a singela contribuição desse estudo.

\section{Referências}

BJELICA, D. Reyes del ajedrez - Bobby Fischer. Madrid: Zugarto Ediciones, 1992.

BOURDIEU, P. Coisas ditas. São Paulo: Brasiliense, 1990a.

BOURDIEU, P. Programa para uma sociologia do esporte. In: BOURDIEU, P. Coisas ditas. São Paulo: Brasiliense, p.207-220, 1990b,.

BOURDIEU, P. Razões práticas: sobre a teoria da ação. Campinas/SP: Papirus, 2007.
BOURDIEU, P.; WACQUANT, L. Una invitación a la sociología reflexiva. 2. ed. Buenos Aires: Siglo XXI Editores Argentina, 2008.

CORDOVIL, J. Diário Popular (Cobertura do mundial de xadrez de 1972). In: TRIFUNOVICTH, P. Fischer-Spassky - Pelo ceptro do xadrez. Lisboa: Editora Presença, 1973.

EDMONDS, D.; EIDINOW, J. Bobby Fischer se fue a la guerra: ele duelo de ajedrez más famoso de la historia. Buenos Aires: Debate, 2007.

ELIAS, N. Introdução a Sociologia. Lisboa: Edições 70, 1980.

ELIAS, N. A sociedade de corte. Rio de Janeiro: Zahar, 2001.

ELIAS, N. Para a fundamentação de uma teoria dos processos sociais. In: ELIAS, N. Escritos \& Ensaios 1: Estado, processo, opinião pública. Rio de Janeiro: Zahar, 2006, pp. 197-231.

FINE, R. The world's great chess games. New York: Dover Publications, 1983.

GARCIA, F. Steinitz and the inception of modern chess. GradExpo, University of Pittsburgh, 2006. Disponível em: $<$ http://www.fedegarcia.net/writings/steinitz.pdf> Acesso em: 17 out. 2009.

GONZÁLEZ, J. M. Y ahora Bobby Fischer Campeón del mundo - $\mathbf{1 1}$ de julio al 1 de septiembre de 1972. Madrid: Gráficas BAS, 1972.

JOHNSON, D. White king and red queen: how the Cold War was fought on the chessboard. London: Atlantic Books, 2007.

KASPAROV, G. Meus grandes predecessores 1: uma história moderna sobre o desenvolvimento do jogo de xadrez. Santana de Parnaíba/SP: Editora Solis, 2004.

KASPAROV, G. Meus grandes predecessores 2: uma história moderna sobre o desenvolvimento do jogo de xadrez. Santana de Parnaíba/SP: Editora Solis, 2005.

KASPAROV, G. Meus grandes predecessores 4: Uma história moderna sobre 0 desenvolvimento do jogo de xadrez. Santana de Parnaíba/SP: Editora Solis, 2006.

LANDSBERG, K. William Steinitz: A biography of the Bohemian Caesar. Jefferson, N. C.: McFarland \& Co., 1993. 
LASKER, E. História do xadrez. 2. ed. São

Paulo: IBRASA, 1999

LOUREIRO, L. Xadrez. In: COSTA, L. P. (org.). Atlas do esporte no Brasil. Rio de Janeiro: CONFEF, 2006, pp. 1008-1024.

MECKING, H. C. O encontro do século Fischer x Spassky. APEC, Visão, 1973.

MILLS, C. W. Usos da história. In: MILLS, C. W. A imaginação sociológica. 4. ed. Rio de Janeiro: Zahar, 1975, pp. 156-187.

MORAN, P. "Bobby" Fischer: su vida y partidas. Barcelona: Ediciones Martinez Roca, 1972.

REVISTA VEJA. Fischer na casa do rei. São Paulo, ed. 205, pp. 60-63, 09 ago. 1972.

SAIDY, A. The Battle of Chess Ideas. London: Batsford, 1972.

SAIDY, A.; LESSING, N. The world of chess. New York: Ridge Press \& Randon House, 1974.

SEGAL, A. S. Campeonato Mundial - Fischer $\mathbf{X}$ Spassky. São Paulo: Editora Brasiliense, 1972.

SOUZA, J. O xadrez em xeque: uma análise sociológica da "história esportiva" da modalidade. 2010. 191f. Dissertação (Mestrado em Educação Física) - Departamento de Educação Física, Universidade Federal do Paraná, Curitiba, 2010.

SOUZA, J.; STAREPRAVO, F.; MARCHI JÚNIOR, W. O processo de constituição históricoestrutural do subcampo esportivo do xadrez: uma análise sociológica . Revista Movimento, Porto Alegre, v. 17, n. 2, p. 93-113, abr./jun. 2011.

STEINITZ, W. The book of the sixth American Chess Congress. New York: P. A. Merian, 1891, $531 \mathrm{p}$.

Agradecimentos: Somos gratos, sobremaneira, ao Clube de Xadrez de Guarapuava/PR que disponibilizou o material bibliográfico para a realização da pesquisa de mestrado que deu origem a esse artigo-síntese.

\section{Endereço:}

Juliano de Souza

José Zagonel Passos, 460 Bairro: Vila Bela

Guarapuava PR Brasil

85027-110

Telefone: (42) 98011221

e-mail: julianoedf@yahoo.com.br

Recebido em: 13 de julho de 2012.

Aceito em: 19 de abril de 2013.

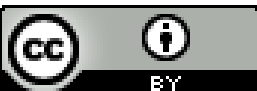

Motriz. Revista de Educação Física. UNESP, Rio Claro, SP, Brasil - elSSN: 1980-6574 - está licenciada sob Creative Commons - Atribuição 3.0 